\title{
Comparison of theoretical deformation with real life model of a steel bridge span
}

\author{
Karol Federowicz ${ }^{1}$ \\ ${ }^{1}$ West Pomeranian University of Technology, Faculty of Civil Engineering and Architecture, \\ al. Piastów 50, Szczecin, Poland
}

\begin{abstract}
The article presents the selection process of a static system and optimization for steel bridge span. The issue was addressed as an entry to a BRICO 2017 contests in designing steel bridges. The proposed solutions were checked in terms of their bearing capacity, technological assembly and economics. General guidelines for geometry selection were described. The designed construction was produced and tested under load to determine the deflection in both vertical and horizontal plane. Furthermore, the article details the joints and technological issues met during the design process. Theoretical calculations and actual measurements on a real life model were compared. The process of structural design of civil engineering structures is a complicated, time consuming multilayered issue. The key to a good design lies in a compromise between esthetics, functionality, capacity exhaustion and technical possibilities.
\end{abstract}

\section{Introduction}

Metal bridges were firstly used in the second half of $18^{\text {th }}$ century in England. The first significant and documented structure was the Iron Bridge on the Severn river in Shropshire, England, built between 1779-1781 [1]. Due to technical difficulties caused by the lack of welding and screw joints, the bridge incorporated feather connection typical for wooden structures. Since then the methods of designing steel structures have been vastly updated. Due to development of material engineering applicable materials underwent fundamental changes [2].

Mechanical properties of steel such as isotropy and high compressive and tensile strength made it one of the most popular construction materials applied in bridge engineering [3]. Development of metallurgy significantly increased the properties of steel. New materials allowed to design structures with longer spans and to use thinner profiles.

Popularity of steel constructions was also boosted by the participation of academic environment. In the past 30 years various bridge design competitions for students gained popularity. The contests try to advert future designers about different aspects of structural design. Future engineers learn to calculate bearing capacity of bridges with maximum reduction in steel usage. Aesthetics and technical feasibility are also taken into consideration.

\footnotetext{
${ }^{1}$ Corresponding author: federowicz-karol@zut.edu.pl
} 
This article presents the design and optimization process of a bridge submitted to BRICO 2017 Nordic Steel Bridge Competition.

\section{Boundary conditions in accordance with BRICO 2017 rules}

The contest requires design and preparing a steel bridge model with a span of 1000x5000 $\mathrm{mm}$ and clearance of $700 \mathrm{~mm}$. The structure was limited to $2000 \mathrm{~mm}$ height.

Single elements were intended not to exceed the dimensions of $250 \times 250 \times 1250 \mathrm{~mm}$ and the weight of $7 \mathrm{~kg}$. The structure should be joined only with welds and screws. The rules allowed the application of M6-M16 screws, up to 8.8 class. Pre-stressed joints and riffled elements or welded screws were forbidden [4].

Except of geometric limitations, the regulations strictly determined the assembly process. The contest site was divided into several zones for storing, assembling and building as seen in Figure 1 below.

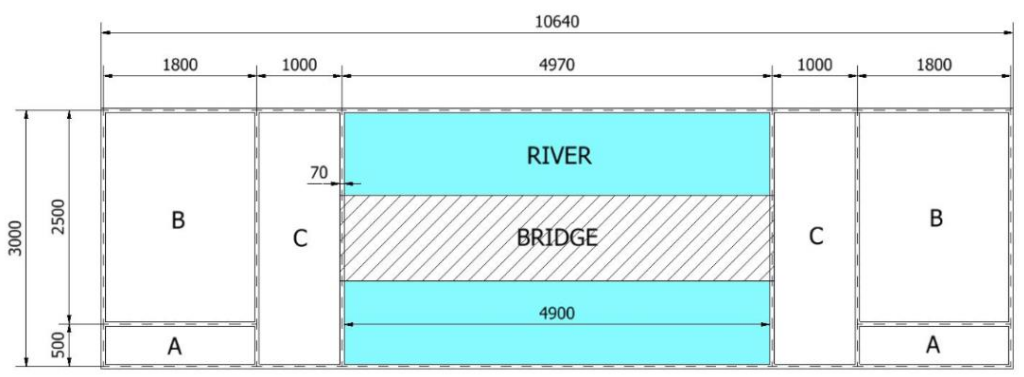

A - Zone for bolts, tools and hard hats

B - Assembly zone

C - Construction zone

Fig. 1. Contest site division [4].

The B zone (Fig. 1) was intended for pre-assembly of maximum 3 parts at a time. The $\mathrm{C}$ zones and River zone were limited to a single team member only. Additionally, in order to reflect real-life conditions construction during assembling could not "touch" the River zone. Temporary supports were allowed, but had to ensure stability and could not exceed $1300 \times 250 \times 250 \mathrm{~mm}$.

The assembly regulations forced the designers to divide the bridge into possibly smallest number of parts. This also required to maintain assembly simplicity and minimal number of joints.

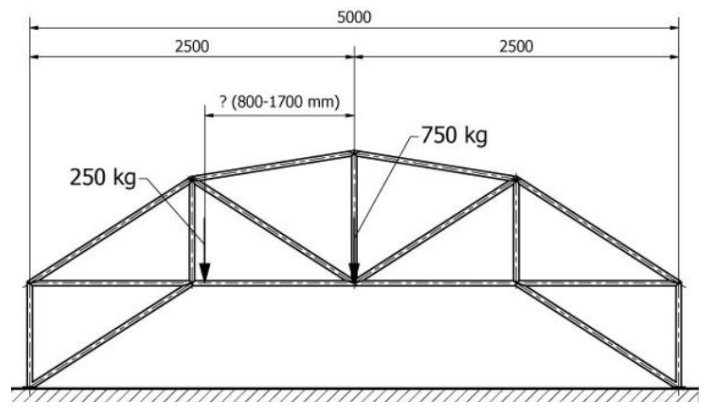

Fig. 2. Vertical loads applied to the bridge [4]. 
In order to evaluate the stability of the bridge, tests were carried out to measure the deformation under load in two-dimensions. The vertical deformation was measured in the center of the span as seen in Figure 2. Two-forces were applied to the bridge. The first one $(750 \mathrm{kG})$ in the middle, the second $(250 \mathrm{kG})$ randomly applied between $800-1700 \mathrm{~mm}$ from the center of the span.

Deformability in a horizontal direction was measured by applying $30 \mathrm{kG}$ vertical load in the middle of the span and $25 \mathrm{kG}$ of force horizontally. The deflections were measured with electronic dial gauge at the lowest point of the structure in the middle of the transversal span.

\section{Selection of model geometry}

The designing process was preceded by several concept calculated in Autodesk Robot Structural Analysis. Each solution was evaluated in terms of structural optimization. The assessment included division of the structure on shipping elements. Total weight of the structure and vertical and horizontal deflections were also taken into account. Advantages and disadvantages of each designed model are described in the further parts of this study.

\subsection{Spatial truss bridge}

The first analysis regarded a beam bridge with deck and supports made of spatial truss (Fig. 3 ). The solution was supposed to exhibit high rigidity in both planes [5]. However, due to geometrical restriction the design was ineffective, utilizing almost $200 \mathrm{~kg}$ of steel. The vertical deflection amounted to $8.2 \mathrm{~mm}$.

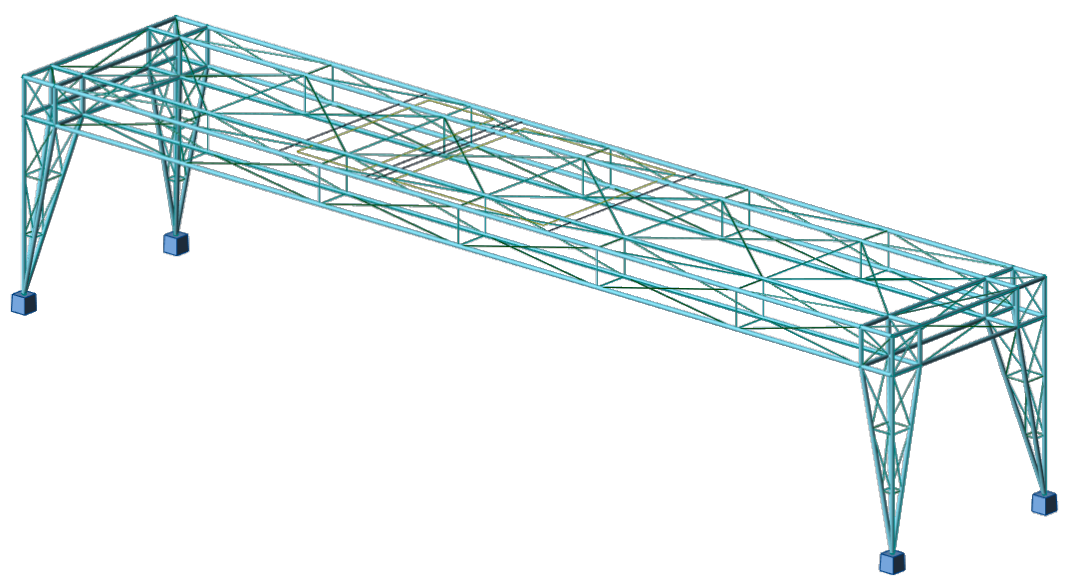

Fig. 3. Spatial truss bridge.

\subsection{Single girded bridge}

Single girder bridge design has reduced the number of elements compared to the previous solution (Fig. 4). This design is often used for reinforced concrete and pre-stressed bridges. The proposed design reduced the overall weight to $96 \mathrm{~kg}$. Additionally, assembly elements were all repetitive, facilitating the assembly. However, reduction to a single central girder increased its susceptibility to torsion. Small dimensions of the spatial truss that build the 
main girder resulted in increased difficulty of assembly process. The joints between the girder and deck bars also posed additional difficulty for installation.

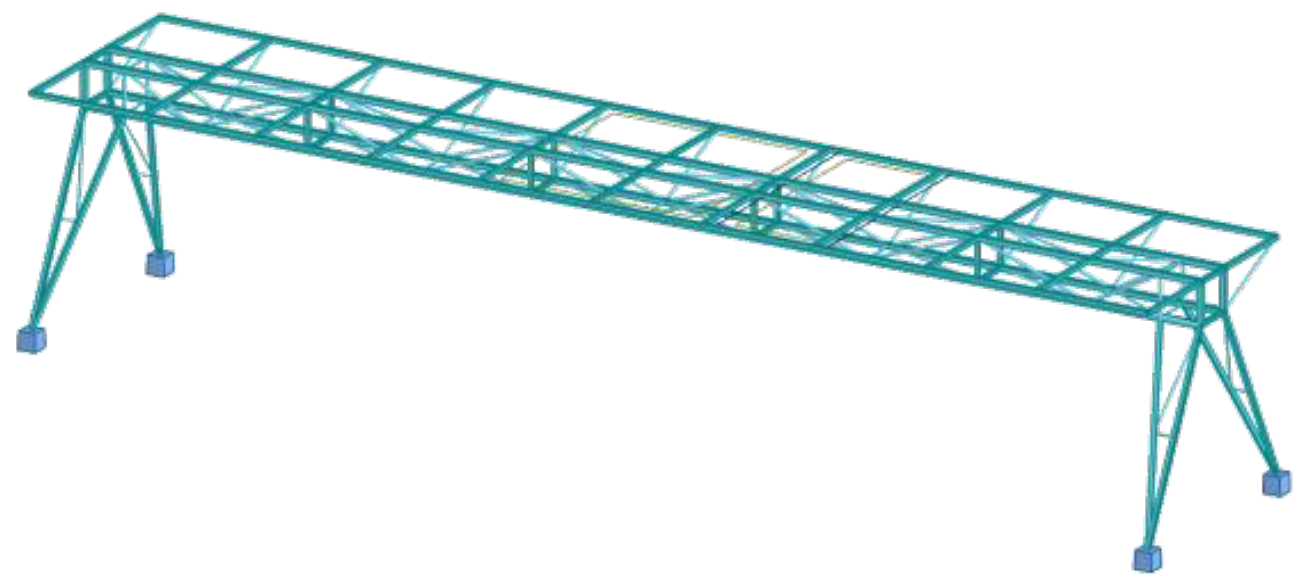

Fig. 4. Single girder bridge.

\subsection{Arched bridges}

Another proposed model consisted of arched bridge. Except of strength and stability, the model showed advantageous visual aesthetics. The arched design allowed the application of thinner steel profiles due to reduction of flexural element. Due to technological difficulty the girder was divided into separate segments (Fig. 5). In order to increase the rigidity in the vertical plane the authors decided to use truss girders. The obtained structure exhibited high rigidity (vertical deflection of $3.2 \mathrm{~mm}$ ). Replacing the spatial trusses with flat girders made the structure more susceptible to horizontal deformation which in turn increased the number of bracings. The solution caused several assembly issues, particularly in the vicinity of joints. The feasibility evaluation proved this issue critical.

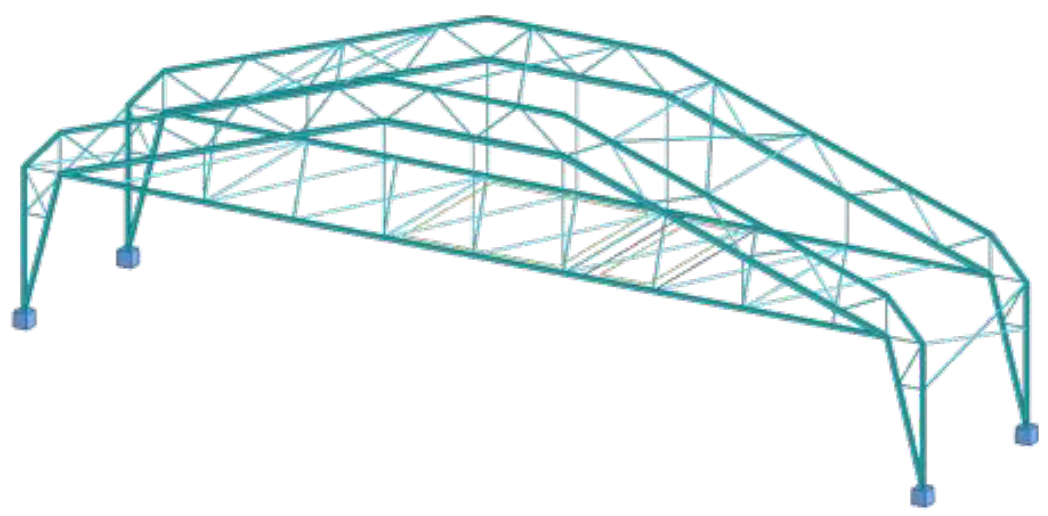

Fig 5. Arched bridge. 


\subsection{Proposed model}

While performing simulations of the proposed models the final one has been chosen for production. The design once again covered of two symmetrical girders providing high rigidity in both planes (Fig. 6). The girder geometry was optimized by switching to triangular build-up. Showing two bars in the top flange and on in the bottom, the geometry had simplified the assembly of the structure. Additionally, the design facilitates the execution of butt joints, which shorten the assembly time [6,7]. Installation of the deck at the level of top flange allowed to reduce the number of bracing, without vertical rigidity decrement.

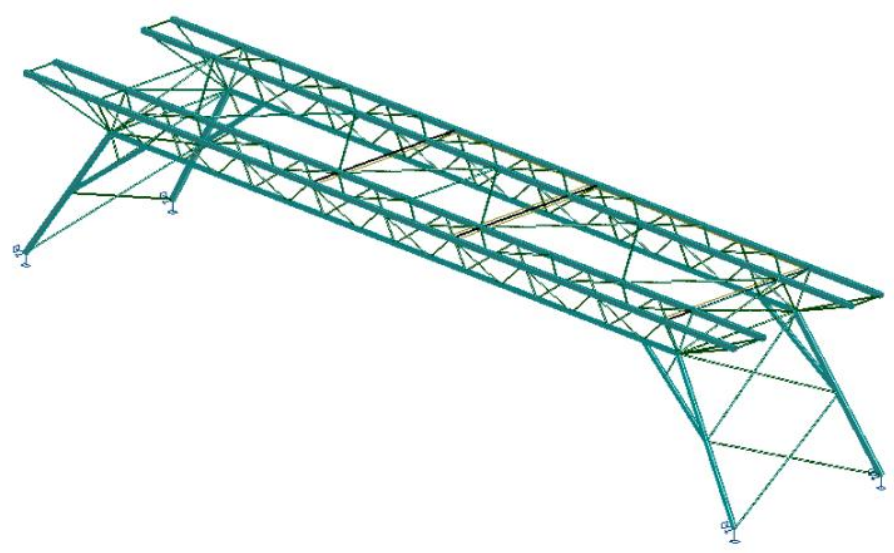

Fig. 6. Final design.

In order to further optimize the structure, the supports were inclined in both planes. This allowed to reduce the final span, thus resulted in decreasing the size of steel profiles. Unfortunately, this method increased the complexity of element production. It was necessary to prepare a $3 \mathrm{D}$ model and required chamfering with special equipment.

\subsubsection{Profile selection}

Designing an optimal construction requires balance between number of profiles and size. Proper optimization results in simplification of assembly and construction while the profiles showed their maximum effort. One of the most important aspects of design is to retain optimal dimension proportions. For freely supported beams [5] the height to span ratio should be between $1 / 20$ to $1 / 25$.

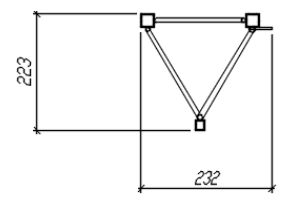

(a)

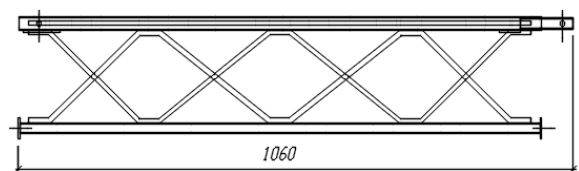

(b)

Fig 7. Assembly element - girder a) cross-section b) side view. 
In the case of a proposed structure the assumed range was $20-25 \mathrm{~cm}$. The structure included 5 profile types only: 3 round bars $\Phi 6, \Phi 8 \Phi 10$ for bracing and lattice, and square channels $20 \times 2$ for tension flange and $25 \times 2$ for compressed flange (Fig. $7 \mathrm{a}$ and $7 \mathrm{~b}$ ). Due to this setup the theoretical total weight amounted $75 \mathrm{~kg}$.

It is necessary to maintain geometrical invariance in girders. It can be done by proper bracing layout during the design of spatial systems [8]. The girder design requires bracing in the compressed flanges. This allows to shorten the buckling length. Due to contest regulations and known horizontal force, the designers decided to use unsymmetrical system of bracing that works only under tension. In real-life structures where load can be applied in different directions, it is recommended to use symmetrical bracing [8]. There are no design guidelines regarding limit slenderness for tension bars. The authors assumed the limit value of $\lambda=320$.

\section{Division of structure into shipped elements}

At the design stage of prefabricated elements it is required to take into account their shipment and assembly. Regarding the contest regulations the bridge was divided into 16 main shipped elements and singular bracing bars. In order to highly shorten the assembly the bracing was screwed with a single bolt to gussets and supports. In order to connect to the girders, steel plugs were used in the top flange and gusset in the bottom. Chosen joints allowed for swift assembly and reduction of screws (Fig. 8a, b).

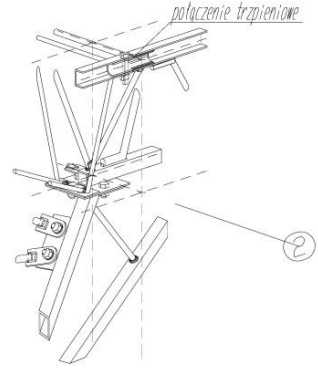

(a)

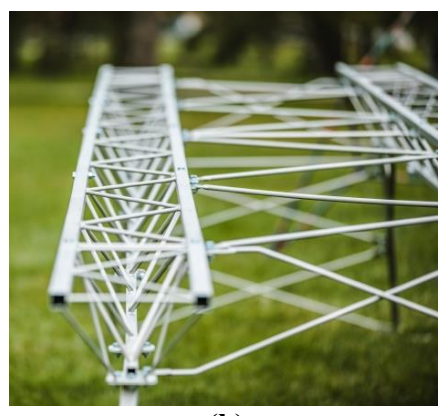

(b)

Fig. 8 (a) Steel plug joint, (b) View of prepared structure.

\section{Validation of proposed model in actual structure}

In order to design complex spatial structures it is necessary to develop detail project. The structure, was modeled and calculated in two CAD software packages: Aveva Bocad and Tekla Structure. After modeling required joints, the total weight of structure amounted to 86 and $83 \mathrm{kG}$ respectively. Theoretical mass calculated in Robot package was $75 \mathrm{~kg}$. The difference occurred due to not incorporating the weight of gussets, screw and welds. It is necessary to consider all existing dead loads while considering calculation model.

The bridge was assembled in a steel prefabrication workshop, which highly increased the precision of the structure (Fig. 9). Structural elements were welded together with semiautomatic MIG welding. This allowed to produce high quality, aesthetic weld for 2 $\mathrm{mm}$ thick elements.

According to the contest regulation the bridge imposed load in two planes. After the test loading with a horizontal force, the measured horizontal deflection amounted to $0.5 \mathrm{~mm}$. Given vertical loading in the center of the span and $1350 \mathrm{~mm}$ from the center (randomly 
chosen value in accordance to regulations) the deflection amounted to $7.45 \mathrm{~mm}$. The calculated theoretical value for assumed system was $7.6 \mathrm{~mm}$.

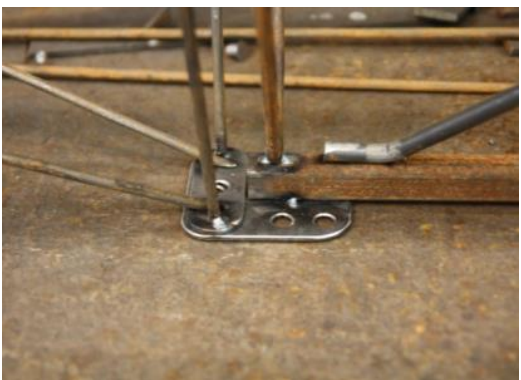

(a)

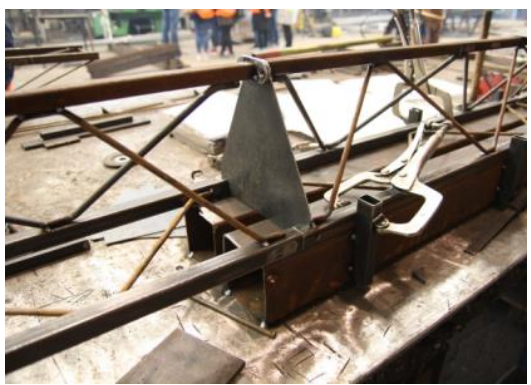

(b)

Fig. 9. (a) Gusset, (b) Structure prefabrication.

\section{Summary}

Structural design is a multiphase analysis of different solutions in order to search for the optimal one. Regarding the BRICO 2017 where not only the esthetics, but also mass and rigidity were taken into consideration it was necessary to find a compromise. Table 1 presents the most important characteristics of the analyzed models. None of the models exceled in every manner. The proposed solution was located in-between rigid massive beam bridge and slender arched bridge.

Table 1. Characteristics of proposed models.

\begin{tabular}{|c|c|c|c|c|}
\hline Bridge & $\begin{array}{c}\text { Number of } \\
\text { assembly parts }\end{array}$ & $\begin{array}{c}\text { Calculated mass } \\
{[\mathbf{k g}]}\end{array}$ & $\begin{array}{c}\text { Theoretical horizontal } \\
\text { deflection [mm] }\end{array}$ & $\begin{array}{c}\text { Theoretical vertical } \\
\text { deflection [mm] }\end{array}$ \\
\hline $\mathbf{3 . 1}$ & 277 & 169 & 0.3 & 8.2 \\
\hline $\mathbf{3 . 2}$ & 166 & 96 & 1.4 & 15.0 \\
\hline $\mathbf{3 . 3}$ & 130 & 74 & 8.9 & 3.2 \\
\hline BRICO & 189 & 75 & 0.3 & 7.4 \\
\hline
\end{tabular}

The comparison of mass between the produced structure $(84.5 \mathrm{~kg})$ and theoretical values from Robot $(75 \mathrm{~kg})$ and Tekla $(83 \mathrm{~kg})$ software clearly shows that despite the calculation precision there are always slight shortcomings. The differences in the model mass calculated with software and actual mass were produced by thin galvanic coating.

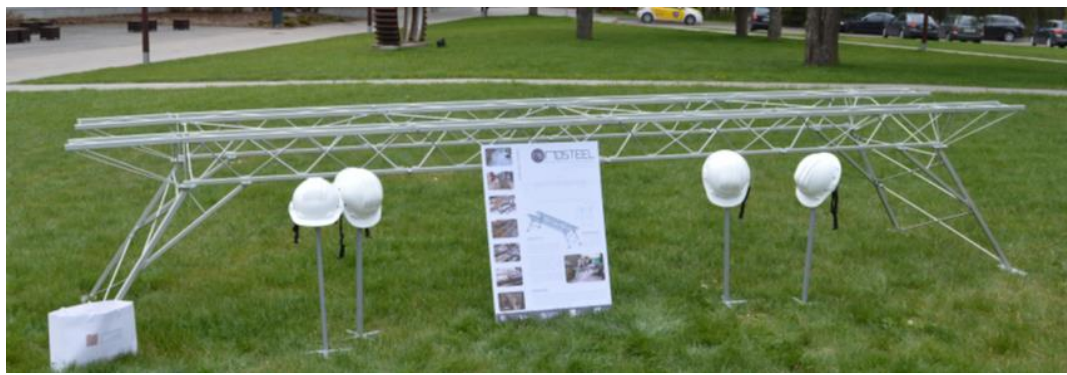

Fig. 10. Assembled construction. 
There are some differences in calculated values and actual measurement of deformations: $0.3 \mathrm{~mm}$ to $0.5 \mathrm{~mm}$ in terms of horizontal deformation and $7.6 \mathrm{~mm}$ to 7.45 $\mathrm{mm}$ in vertical deformation. There are several reasons for this combination. The most important is the simplification of node rigidity in calculations. The software always assumes ideal hinge or fixed support which constitutes to slight differences caused by backlash in actual structure (Fig. 11b). The same problem occurs with screws where there is always a bit of space between the actual screw and the hole. Additionally, unsymmetrical loading of the construction can create eccentricity. While subjected to unsymmetrical load or structural elements outside the plane, the structure starts to exhibit torsion. This issue is usually excluded from the calculations (Fig. 11a).

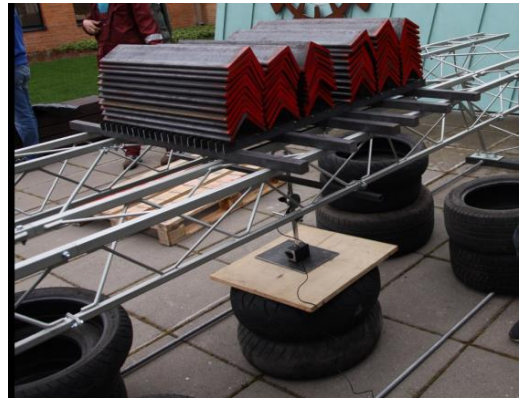

(a)

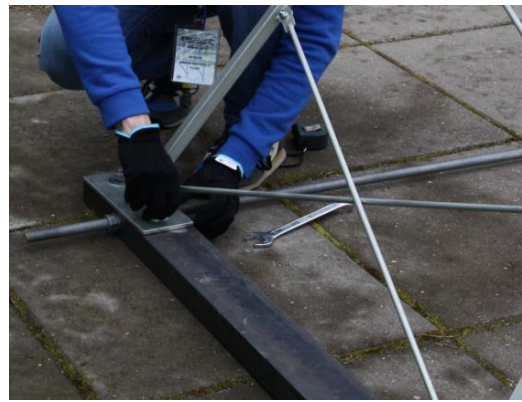

(b)

Fig. 11. (a) Test loading, (b) Structure fixing.

The studied case of bridge design showed that it is necessary to include production and assembly technology. The use of continuous girder lattice significantly simplified the assembly of construction. Steel plug joints in girders allowed to shorten the assembly time to 14 minutes and 20 seconds.

The article clarifies that structural design is a complex, time consuming and multilayered the problem of structural designing problem indeed. A properly constructed structure combines esthetics, functionality, strength and feasibility. In case of civil engineering structures there are no perfect solutions that combine all of the above issues.

\section{References}

1. N. Cossons, B. Trinder, The Iron Bridge: Symbol of the Industrial Revolution, Bradforn-on-Avon: Moonraker Press (1979)

2. S. Smiles, Industrial Biography: Iron Workers and Tool Makers, Bremen: Europaeischer Hochschulverlag GmbH \& Co. KG (2010)

3. K. Rykaluk, Konstrukcje stalowe, podstawy i elementy, Wrocław: Dolnośląskie Wydawnictwo Edukacyjne (2001)

4. BRICO 2017, 2016, Rules and regulations, Tallinn (2016)

5. J. Biliszczuk, et al. Projektowanie stalowych kładek dla pieszych, Wrocław: Dolnośląskie Wydawnictwo Edukacyjne (2004)

6. PN-EN 1993-1-1: 2006, Reguły ogólne i reguły dla budynków

7. PN-EN 1993-1-8: 2006, Projektowanie węzłów

8. A. Biegus, Stalowe budynki halowe, Warszawa: Arkada (2005) 